\title{
Better Safe than Sorry: Prevention of Esophagojejunostomy Leak by Intraoperative Methylene Blue Test in Advanced Gastric Cancer
}

\author{
K. Sędłak ${ }^{1} \cdot{\text { Karol Rawicz-Pruszyński }{ }^{1} \text { (D) } \cdot \text { R. Mlak }{ }^{2} \cdot \text { J. Mielko }^{1} \cdot \mathrm{K}^{\text {Gęca }}{ }^{1} \cdot \text { W. P. Polkowski }}^{{ }^{1}}$
}

Received: 9 September 2020 / Accepted: 12 January 2021 / Published online: 9 February 2021

(C) 2021 The Author(s)

Keywords Gastric cancer · Esophagojejunostomy leak · HIPEC $\cdot$ Methylene blue

\section{Introduction}

Total gastrectomy is a complex procedure with a high risk of complications. ${ }^{1}$ Although the percentage of complications after gastrectomy has recently decreased, the reoperation rate remains steady. ${ }^{1}$ Since the esophagojejunostomy leak (EJL) stays a critical postoperative complication in 5 to $14 \%$ of patients, it is essential to establish appropriate method of EJL prevention. ${ }^{2,3}$ Intraoperative methylene blue test (MBT) is one of few methods described so far and is potentially underestimated. ${ }^{4}$ The results of the MBT to check esophagojejunostomy (EJ) integrity suggest benefits, such as early recognition of EJL and possibility for immediate repair. ${ }^{5}$

The aim of this study was to verify the utility of intraoperative MBT in the prevention of the EJL after gastrectomy for advanced GC.

\section{Materials and Methods}

One hundred fourteen consecutive patients with the esophagojejunostomy following total gastrectomy or proximal gastric resection and double-tract reconstruction (DTR) in whom the MBT was performed intraoperatively were suitable for analysis.

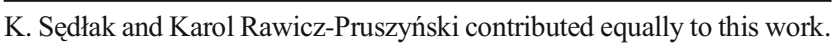

Karol Rawicz-Pruszyński

krpruszynski@gmail.com

1 Department of Surgical Oncology, Medical University of Lublin, Radziwiłłowska 13 St., 20-080 Lublin, Poland

2 Department of Human Physiology, Medical University of Lublin, Radziwiłłowska 11 St., 20-080 Lublin, Poland

\section{Intraoperative Methylene Blue Test Technique}

After completion end-to-side EJ, the integrity of anastomosis was tested by injection of methylene blue solution ( $2 \mathrm{ml}$ of methylene blue dissolved in $100 \mathrm{ml}$ of $0.9 \% \mathrm{NaCl}$ ) using a nasojejunal (NJ) tube at pressure of $20 \mathrm{kPa}$. NJ tube was placed proximal to anastomosis, and jejunum distal to anastomosis was clamped. Sterile gauze was used to cover anastomosis and reveal the potential site of a leak if present. The intraoperative leak was defined as the presence of administered dye solution on a gauze. If a solitary leak was found, additional stitches over the suture line were placed, and the test was repeated.

\section{Results}

The clinicopathological features of the 114 patients included in the study are shown in Table 1. The intraoperative leak was found in $10(8.8 \%)$ patients. The postoperative leak was found in $5(4.4 \%)$ patients. This means that in 5 cases, postoperative leak might have been prevented by MBT. Two patients with a postoperative leak died in the hospital: one among the leaks detected by intraoperative MBT (33.3\%) and one among the postoperatively detected cases $(50 \%)$. The anastomotic leak occurred most frequently in patients with pT3 tumors - two patients (40\%) and pT4a tumors - two patients (40\%). Longer hospitalization time was observed in patients with EJL (29 vs. 11 days; $p=0.0023$ ). Similarly, significantly longer ICU stay was observed in patients with EJL (12 vs. 4 days; $p=0.0071)$. Sensitivity, specificity, positive predictive value (PPV), negative predictive value (NPV), and overall accuracy of the intraoperative MBT in the prediction of the postoperative, clinically apparent EJL were 60\% (95\%CI: 14.7-94.7\%), 93.4\% (95\%CI: 87.2-97.4\%), 30\% (95\%CI: 13.5-54.1\%), $98.1 \%$ (95\%CI: 94.6-99.3\%), and 92.1\% (95\%CI: 85.5-96.3\%) 
Table 1 Clinicopathological variables of all patients included in the study

\begin{tabular}{|c|c|}
\hline Variable & No. of patients $n=114(\%)^{*}$ \\
\hline \multicolumn{2}{|l|}{ Sex } \\
\hline Male & $67(58.8 \%)$ \\
\hline Female & $47(41.2 \%)$ \\
\hline \multicolumn{2}{|l|}{ Age (years) } \\
\hline Average & 57.9 \\
\hline Standard deviation $( \pm)$ & 12.5 \\
\hline Median (min-max) & $58(28-80)$ \\
\hline \multicolumn{2}{|l|}{ Lauren histological type } \\
\hline Intestinal & $42(37.0 \%)$ \\
\hline Mixed & $33(28.7 \%)$ \\
\hline Diffuse & $39(34.3 \%)$ \\
\hline \multicolumn{2}{|l|}{$\mathrm{pT}$} \\
\hline T0 & $5(4.5 \%)$ \\
\hline T1a & $1(0.9 \%)$ \\
\hline $\mathrm{T} 1 \mathrm{~b}$ & $6(5.4 \%)$ \\
\hline $\mathrm{T} 2$ & $17(15.3 \%)$ \\
\hline $\mathrm{T} 3$ & $48(42.3 \%)$ \\
\hline $\mathrm{T} 4 \mathrm{a}$ & $23(19.8 \%)$ \\
\hline $\mathrm{T} 4 \mathrm{~b}$ & $14(11.7 \%)$ \\
\hline \multicolumn{2}{|l|}{$\mathrm{pN}$} \\
\hline No & $45(40.9 \%)$ \\
\hline N1 & $13(11.8 \%)$ \\
\hline $\mathrm{N} 2$ & $19(17.3 \%)$ \\
\hline N3a & $22(20.0 \%)$ \\
\hline $\mathrm{N} 3 \mathrm{~b}$ & $11(10.0 \%)$ \\
\hline \multicolumn{2}{|l|}{ pM } \\
\hline M0 & $84(73.7 \%)$ \\
\hline M1 & $30(26.3 \%)$ \\
\hline \multicolumn{2}{|l|}{ Neoadjuvant chemotherapy } \\
\hline Yes & $81(71.1 \%)$ \\
\hline No & $33(28.9 \%)$ \\
\hline \multicolumn{2}{|l|}{ Reconstruction method } \\
\hline TG (Roux-en-Y) & $98(86.0 \%)$ \\
\hline PG (DTR) & $16(14.0 \%)$ \\
\hline \multicolumn{2}{|c|}{ Intraoperative leak detected by MBT } \\
\hline Yes & $10(8.8 \%)$ \\
\hline No & $104(91.2 \%)$ \\
\hline \multicolumn{2}{|c|}{ Clinically apparent postoperative leak } \\
\hline Yes & $5(4.4 \%)$ \\
\hline No & $109(95.6 \%)$ \\
\hline \multicolumn{2}{|l|}{ CCI } \\
\hline Average & 17.4 \\
\hline Standard deviation $( \pm)$ & 26.1 \\
\hline Median (min-max) & $0(0-100)$ \\
\hline \multicolumn{2}{|l|}{ Hospitalization time (days) } \\
\hline Average & 12.9 \\
\hline Standard deviation $( \pm)$ & 8.2 \\
\hline Median (min-max) & $11(4-59)$ \\
\hline \multicolumn{2}{|l|}{ ICU hospitalization } \\
\hline Yes & $21(18 \%)$ \\
\hline No & $93(82 \%)$ \\
\hline
\end{tabular}

$E J L$ esophagojejunostomy leak, $C C I$ comprehensive complication index, $I C U$ intensive care unit, $T G$ total gastrectomy, $P G(D T R)$ proximal gastrectomy with double-tract reconstruction 


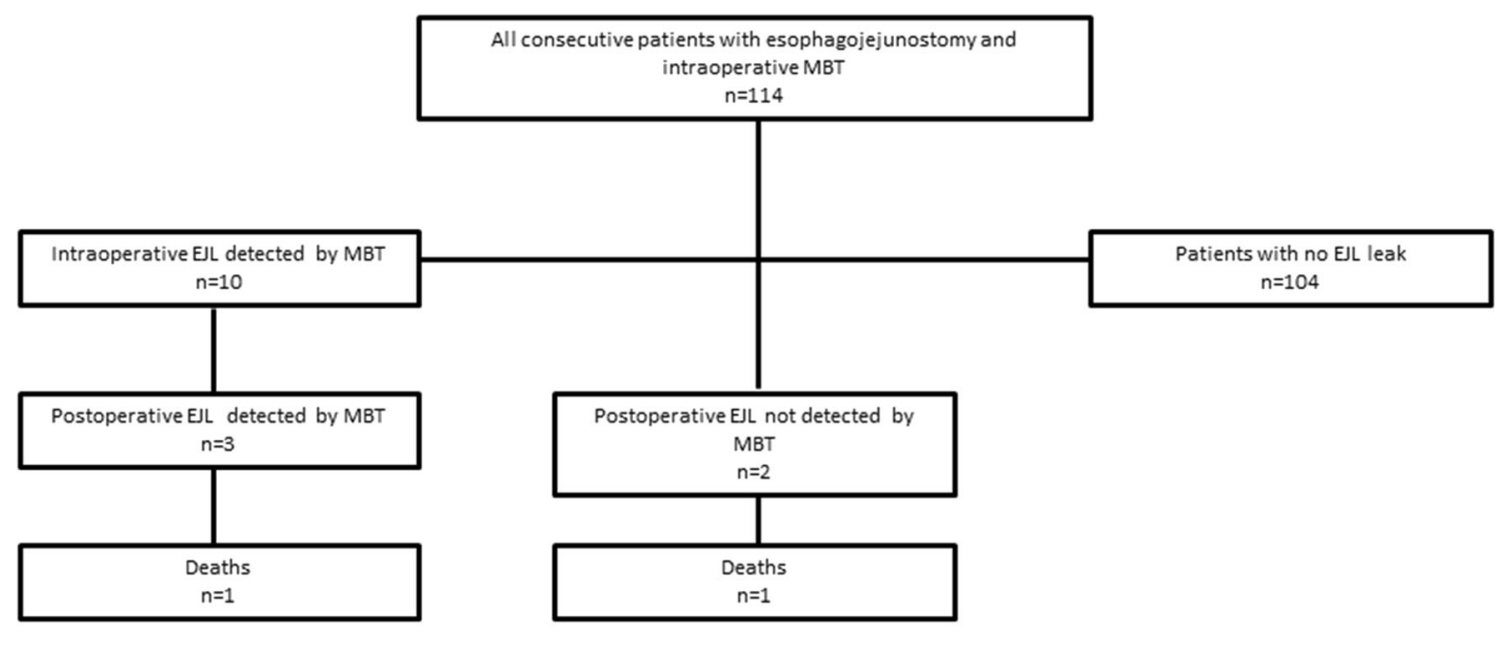

EJL - esophagojejunostomy leak; MBT - methylene blue test

Fig. 1 Algorithm of intraoperative and postoperative EJL. EJL. esophagojejunostomy leak; MBT. methylene blue test

respectively. The algorithm of intraoperative and postoperative EJL is presented in Fig. 1.

\section{Discussion}

The present study was undertaken to evaluate the utility of intraoperative MBT in the prevention of the EJL. Although the intraoperative MBT did not eliminate postoperative EJL, it might have reduced the number of postoperative clinical leaks by allowing the repair of the intraoperatively detected ones.

In recent report on perioperative complications from $\mathrm{GC}$ referral centers in 11 European countries belonging to the Gastrectomy Complications Consensus Group (GCCC), ${ }^{6}$ the most frequent surgical complication was anastomotic leak $(9.8 \%)$. Authors suggest that portion of leaks may be linked to the employed surgical technique, calling for improvement in the learning strategy. It may be assumed that the reduced rate of EJL in our center $(4.4 \%)$ was accomplished with a routine use of MBT. This study contains certain limitations: lack of postoperative upper gastrointestinal series, non-standardized definition of EJL leak, and, since there was no standardized way that the patients were tested for leak postoperatively, definitive conclusions about causation cannot be made.

\section{Conclusion}

The MBT may reduce the amount of clinically apparent EJL.

Open Access This article is licensed under a Creative Commons Attribution 4.0 International License, which permits use, sharing, adaptation, distribution and reproduction in any medium or format, as long as you give appropriate credit to the original author(s) and the source, provide a link to the Creative Commons licence, and indicate if changes were made. The images or other third party material in this article are included in the article's Creative Commons licence, unless indicated otherwise in a credit line to the material. If material is not included in the article's Creative Commons licence and your intended use is not permitted by statutory regulation or exceeds the permitted use, you will need to obtain permission directly from the copyright holder. To view a copy of this licence, visit http://creativecommons.org/licenses/by/4.0/.

\section{References}

1. Yi HW, Kim SM, Kim SH, et al. Complications leading reoperation after gastrectomy in patients with gastric cancer: frequency, type, and potential causes. J Gastric Cancer. 2013;13(4):242-6. doi: https://doi. org/10.5230/jgc.2013.13.4.242

2. Deguchi $Y$, Fukagawa $T$, Morita $S$, et al. Identification of risk factors for esophagojejunal anastomotic leakage after gastric surgery. World J Surg. 2012 Jul;36(7):1617-22. doi: https://doi.org/10.1007/s00268-012-1559-3.

3. Gong W, Li J. Combat with esophagojejunal anastomotic leakage after total gastrectomy for gastric cancer: A critical review of the literature. Int J Surg. 2017;47:18-24. doi: https://doi.org/10.1016/j.ijsu.2017.09.019.

4. Celik S, Almali N, Aras A, et al. Intraoperatively Testing the Anastomotic Integrity of Esophagojejunostomy Using Methylene Blue. Scand J Surg. 2017;106(1):62-67. doi: https://doi.org/10. $1177 / 1457496916630652$

5. Smith S, McGeehin W, Kozol RA, et al. The efficacy of intraoperative methylene blue enemas to assess the integrity of a colonic anastomosis. BMC Surg. 2007;7:15. doi: https://doi.org/10.1186/1471-2482-7-15

6. Baiocchi GL, Giacopuzzi S, Reim D, Piessen G, Costa PMD, Reynolds JV, Meyer HJ, Morgagni P, Gockel I, Santos LL, Jensen LS, Murphy T, D'Ugo D, Rosati R, Fumagalli Romario U, Degiuli M, Kielan W, Mönig S, Kołodziejczyk P, Polkowski W, Pera M, Schneider PM, Wijnhoven B, de Steur WO, Gisbertz SS, Hartgrink H, van Sandick JW, Botticini M, Hölscher AH, Allum W, De Manzoni G. Incidence and Grading of Complications after Gastrectomy for Cancer Using the GASTRODATA Registry: A European Retrospective Observational Study. Ann Surg. 2020. doi: https://doi.org/10.1097/SLA.0000000000004341.

Publisher's Note Springer Nature remains neutral with regard to jurisdictional claims in published maps and institutional affiliations. 